\title{
Combined transcatheter aortic valve replacement and endovascular ascending aortic repair: Fiction or reality?
}

\author{
Ourania Preventza, MD, and Joseph S. Coselli, MD
}

See related article on pages e59-60.

This case report by Wilbring and colleagues ${ }^{1}$ describes an entirely endovascular therapeutic approach to both calcific aortic valve stenosis and DeBakey type II aortic dissection. They carried out an endovascular repair of the ascending aorta with a Bolton NBS endograft $(34 \mathrm{~mm}$ proximal diameter $\times 34 \mathrm{~mm}$ distal diameter $\times 109 \mathrm{~mm}$ length; Bolton Medical, Inc, Sunrise, Fla) with rapid pacing by transfemoral access. This was followed by percutaneous transcatheter aortic valve replacement, also transfemoral, with a 29-mm Medtronic CoreValve (Medtronic Inc, Minneapolis, Minn). Since the Edwards Sapien Transcatheter Heart Valve THV (Edward Lifesciences, Irvine, Calif) and the Medtronic CoreValve were approved for commercial use by the US Food and Drug Administration for patients with calcific aortic valvular stenosis who are of advanced age and have multiple prohibitive comorbidities, such as the individual described by Wilbring and colleagues, ${ }^{1}$ transcatheter aortic valve replacement has become an approach of increasing frequency, if not the standard of care. Transcatheter aortic valve replacement is often denied patients with aortic valvular stenosis who have concomitant ascending aortic pathology. Consequently, Wilbring and colleagues ${ }^{1}$ should be congratulated for their innovative therapeutic approach to address both pathologies in a single endovascular setting.

Currently, there is no established endovascular repair for proximal ascending aortic pathology. Within the literature, there are a number of care reports and a few small series, all with variable results, usually treating isolated problems such as pseudoaneurysms. Currently approved endovascular

\footnotetext{
From the Department of Cardiovascular Surgery, the Texas Heart Institute, Houston, Tex; and the Division of Cardiothoracic Surgery, Michael E. DeBakey Department of Surgery, Baylor College of Medicine, Houston, Tex.

Disclosures: W. L. Gore \& Associates and Cook Medical, Inc, have provided travel expenses for O.P. in the past. O.P. serves as a consultant for Medtronic, Inc. J.S.C. was provided program support by and has given lectures for W. L. Gore \& Associates, and he serves as principal investigator for clinical trials conducted by W.L. Gore \& Associates, Medtronic, Inc, and Cook Medical, Inc. In addition, J.S.C. serves as a consultant to and receives royalties from Vascutek Ltd, a subsidiary of Terumo Corporation. The other author has nothing to disclose with regard to commercial support.

Received for publication Feb 8, 2015; accepted for publication Feb 9, 2015.

Address for reprints: Ourania Preventza, MD, BCM 390, One Baylor Plaza, Houston, TX 77030 (E-mail: opsmile01@aol.com).

J Thorac Cardiovasc Surg 2015;149:e61

$0022-5223 / \$ 36.00$

Copyright (c) 2015 by The American Association for Thoracic Surgery

http://dx.doi.org/10.1016/j.jtcvs.2015.02.013
}

stent grafts for the descending thoracic and abdominal aorta are not specifically designed for, nor are they suitable for, the ascending aorta. The average length of the ascending aorta is approximately $8 \mathrm{~cm}$, and available thoracic endografts have a minimum length of $10 \mathrm{~cm}$, increasing the risk of occluding either the coronaries or the innominate artery. The curved anatomy of the ascending aorta, the variable diameter proximally and distally, as well as the more profound hemodynamic aspects have made adapting current endograft technology to this segment of the aorta challenging. In cases of proximal aortic pseudoaneurysm, multiple abdominal aortic cuffs have been used with modest success, and results have been variable.

The potential management of proximal aortic dissection as a consequence of the usual complex aortic features is especially daunting. Adequate landing zones proximally and distally are usually not available, and because of the frequent presence of distal reentry sites, elimination of the false lumen, even with complete coverage of the inciting tear, remains problematic. As Wilbring and colleagues ${ }^{1}$ point out, the clinical configuration of aortic stenosis and DeBakey type II aortic dissection isolated to the ascending aorta with proximal and distal landing zones remains a rarity. It is commendable, however, that Wilbring and colleagues ${ }^{1}$ were able to identify such a case and manage both the aortic valve and ascending aorta completely endovascularly. The report highlights the need for continued efforts in collaboration between surgeons and industry to evolve the current technology to address ascending aortic pathology, including aortic dissection, as well as the aortic root to provide therapeutic and endovascular approaches to individuals not suited to open repair and even those who are faced with an open repair carrying excessive mortality and morbidity risk.

\footnotetext{
Reference

1. Wilbring M, Ghazy T, Matschke K, Kappert U. Complete endovascular treatment of acute proximal ascending aortic dissection and combined aortic valve pathology. J Thorac Cardiovasc Surg. 2015;149:e59-60.
} 